\title{
Controversies in Establishing Biosimilarity: Extrapolation of Indications and Global Labeling Practices
}

\author{
Hans C. Ebbers ${ }^{1,2} \cdot$ Paul Chamberlain ${ }^{3}$
}

Published online: 13 January 2016

(c) The Author(s) 2016. This article is published with open access at Springerlink.com

\begin{abstract}
The principles of establishing biosimilarity are to demonstrate structural and functional similarity to a reference product using the most discriminatory analytical methods. There is still considerable controversy on the scientific basis for extrapolation of indications for biosimilars, which has been strengthened by diverging global regulatory decision making. Closely related to the question of extrapolation is the question of how to communicate the evidence base for authorizing biosimilars to healthcare professionals. In this paper we will consider some of the discussions around extrapolation of indications and the implications of decisions of various regulatory agencies in the world regarding the authorization and labeling of biosimilars.
\end{abstract}

Paul Chamberlain

paul.chamberlain@ndareg.com

Hans C. Ebbers

h.ebbers@uu.nl

1 Department of Pharmaceutical Sciences, Faculty of Science, Utrecht Institute for Pharmaceutical Sciences, Utrecht University, Utrecht, The Netherlands

2 Utrecht Centre of Excellence for Affordable Biotherapeutics for Public Health, Utrecht, The Netherlands

3 NDA Advisory Services Ltd, Prime House, Challenge Court, Barnett Wood Lane, Leatherhead, Surrey KT22 7DE, UK

\section{Key Points}

There are considerable differences in regulatory decision making in terms of extrapolation of indications.

Currently available data do not suggest any concerns on extrapolating immunogenicity across indications.

Opportunities for savings exist with advanced new treatments and improved disease management.

\section{Introduction}

Biosimilar regulatory pathways have been established around the world to provide an abbreviated route for copy versions of biologicals, so-called biosimilars. The aim of the procedure is to demonstrate physico-chemical and functional similarity to an already authorized reference product, to an adequately rigorous level, that enables comparative clinical studies to focus on evaluating the impact of any detected differences using the most sensitive clinical parameters-rather than to demonstrate overall clinical benefit versus risk per se. If this is done successfully, a product is termed biosimilar and can rely on the clinical experience obtained with its reference product. Extrapolation is the foundation of the biosimilar regulatory framework and is here defined as granting regulatory approval for indications of the reference medicine that are not specifically studied during the clinical development of the biosimilar medicine [1]. This tailored regulatory package allows biosimilars to be marketed at competitive prices. 
To date, 13 distinct biosimilar drug substances (representing six different molecules) have received marketing approval in the EU and an increasing number is in development. The majority of the first approved biosimilars concerned recombinant homologs of naturally occurring proteins (i.e., somatropin, epoetin, filgrastim, follitropin, and insulin glargine). The next wave of biosimilars will largely consist of monoclonal antibodies, which are mainly used in the oncology and immunology setting [2]. These products are more complex structurally, but also pose considerable challenges to investigate clinically, particularly in the oncology setting [3]. In 2013, the first biosimilar monoclonal antibody obtained marketing authorization in the EU, CT-P13, which is a biosimilar version of the tumor necrosis factor $\alpha$ (TNF $\alpha$ )-targeting monoclonal antibody infliximab and is sold under the brand names Inflectra ${ }^{\circledR}$ (Hospira) and Remsima ${ }^{\circledR}$ (Celltrion/Orion Pharma). Several other products are currently under review at regulatory agencies.

Much debate has centered on which data is required to grant an approval for all indications of the product that is already authorized on the market, the reference product [4,5]. Despite this practice being well established in relation to the implementation of manufacturing changes for innovator products, there is still controversy on the scientific basis for extrapolation of indications for biosimilars $[6,7]$. Should the applicant provide comparative clinical data for all authorized indications of the original product, or can all indications be granted using comparative clinical data in a subset of approved indications and the others granted through extrapolation based on scientific grounds; and is clinical data always required to obtain a marketing authorization as a biosimilar? Various learned societies have taken the position that extrapolation of indications should never be allowed and that clinical data should be required for all indications [8-10]—a view that would effectively raise the regulatory standards for biosimilars above those applied for approval of major manufacturing changes for innovator products. Closely related to the question of extrapolation is the question of how to communicate the evidence base for authorizing biosimilars to healthcare professionals. Here we will consider some implications of decisions of various regulatory agencies in the world regarding the extrapolation and labeling of biosimilars.

\section{Extrapolation Controversies}

In all regulatory regions that have adopted biosimilar regulations, including the WHO guidelines on evaluation of similar biotherapeutic products, extrapolation is possible depending on the overall evidence of similarity provided from the comparability exercise and with adequate scientific justification [11]. Extrapolation should take into account the shared mechanism(s) of action in the requested indications and the nature of the potential risks in the different patient populations. For the first biosimilars, extrapolation was relatively straightforward, as the pharmacological actions in the different indications are mostly mediated via the same receptors. Epoetin, for example, is a recombinant version of an endogenous hormone that increases red blood cells through the promotion, survival, proliferation, and differentiation of erythrocytic progenitors [12]. Epoetin has multiple indications, but is mainly prescribed in patients with anemia resulting from chronic kidney disease (CKD) and to prevent transfusions in chemotherapy-induced anemia. There is only one known erythropoietin receptor and the mechanism of action is thus considered to be the same for both indications. However, patients with CKD are more responsive to epoetin and lower doses are required for a therapeutic response. Furthermore, a key safety concern for epoetin, the occurrence of anti-drug antibodies resulting in pure red cell aplasia, has only been reported in CKD patients and not in patients receiving epoetin for chemotherapy-induced anemia. Thus, providing pivotal clinical data in CKD allows the authorization of biosimilar epoetins in chemotherapy-induced anemia. Of note, for biosimilar epoetins currently authorized in the EU, pivotal data in CKD was accompanied by uncontrolled supportive data in the oncology setting.

For monoclonal antibodies, extrapolation is more complex as their mechanism of action may depend on multiple sites of the molecule. Furthermore, often no direct pharmacodynamic marker exists for their activity, which means that clinical studies are designed around (insensitive) clinical end points, which makes it particularly challenging to study these products in some oncology settings. How the different structure-activity relationships of antibodies contribute to efficacy and safety in the different indications is often not fully understood. This incomplete knowledge has been the basis for a controversy surrounding the biosimilar infliximab CT-P13. In July 2014, following a positive opinion of the Committee for Medicinal Products for Human Use (CHMP), the European Commission granted a marketing authorization to CT-P13 and granted all indications for which Remicade ${ }^{\circledR}$ was approved based on three clinical studies that included rheumatoid arthritis (RA) patients and ankylosing spondylitis (AS) patients. Health Canada also approved CT-P13, but stated that "extrapolation to indications and uses pertaining to Crohn's disease (CD) and ulcerative colitis (UC) could not be recommended due to differences between CT-P13 and the reference product, that could have an impact on the clinical safety and efficacy of these products in these indications" [13]. In other regulatory regions, CT-P13 has not received marketing authorization for the pediatric UC and CD indications [14]. 
The scientific basis for the differing views between EMA and Health Canada apparently lies in observed differences between CT-P13 and Remicade ${ }^{\circledR}$ in afucosylated glycans, which was associated with detectable differences in the binding affinity of the therapeutic monoclonal antibody to the Fc $\gamma$ RIIIa and Fc $\gamma$ RIIIb receptors as determined by surface plasmon resonance. The observed difference in Fc $\gamma$ RIIIb affinity did not lead to measurable differences in binding to neutrophils and was not considered further. Fc $\gamma$ RIIIa is involved in antibody-dependent cellular cytotoxicity (ADCC). In the majority of directly comparative in vitro ADCC assays performed, there was no detectable difference between CT-P13 and Remicade ${ }^{\circledR}$. In contrast, a difference in ADCC was detected using a sensitive enriched natural killer (NK) cell assay, from cells isolated from donors and CD patients, in combination with a target cell line that expresses supra-physiological levels of the target antigen, tmTNF $\alpha$. The applicant investigated this further and found that these differences were not observed in assays using whole blood, peripheral blood mononuclear cells, or neutrophils as effector cells. The Fc $\gamma$ RIIIa receptor exists as three polymorphic variants $\mathrm{V} / \mathrm{V}, \mathrm{V} / \mathrm{F}$, and $\mathrm{F} / \mathrm{F}$ and significant differences were observed in the $\mathrm{V} / \mathrm{V}$ and $\mathrm{V} / \mathrm{F}$, but not the F/F subgroup. The experiments were also performed with added (diluted) serum from patients to mimic the biological situation. In the presence of serum, the earlier observed differences were no longer observed, consistent with the results from other studies using more "physiological' assay conditions [15]. The EMA considered the observed difference in a single, highly sensitive NK assay not to be representative of the physiological situation. Based on the same data, Health Canada concluded that, because ADCC may be an active mechanism of action for infliximab in the setting of inflammatory bowel disease (IBD), extrapolation to $\mathrm{CD} / \mathrm{UC}$ cannot be recommended in the absence of clinical studies in IBD_-despite the absence of direct evidence to support this notion $[16,17]$. The impact of different Fc $\gamma$ RIIIa polymorphisms has been evaluated through genotyping $\mathrm{CD}$ patients. While these have been linked to an increase in ADCC activity in in vitro assays, as of yet no link to clinical outcome has been established [18, 19]. While ADCC may play a role in the therapeutic effect of infliximab, many differences between different $\mathrm{TNF} \alpha$ inhibitors may underlie the observed differences in efficacy in $\mathrm{CD}$ and UC, including dosing, half-life, TNF $\alpha$-binding affinity, Complement Dependent Cytotoxicity (CDC) activity, and reverse signaling via transmembrane TNF $\alpha$ [20, 21]. Nevertheless, an influence of ADCC cannot be excluded.

A copy of adalimumab ZRC-3197 (Exemptia $^{\circledR}$ ) was licensed as a biosimilar to Humira $^{\circledR}$ in India [22, 23]. Humira $^{\circledR}$ is not authorized in India, but Indian guidelines allow a biosimilar product to be authorized if the reference product is licensed and widely marketed for at least 4 years in a country with a well established regulatory framework [24]. The product was approved on the basis of comparative physicochemical characterization and a comparative clinical trial versus Humira ${ }^{\circledR}$ including 120 RA patients (60 per arm) [25]. The trial lasted 12 weeks and was designed as a superiority study rather than and equivalence or noninferiority study [25]. Based on the dossier, ZRC-3197 was approved for RA, juvenile idiopathic arthritis, AS, psoriatic arthritis, UC and CD, but interestingly not for the treatment of psoriasis. The reason for not authorizing the product for psoriasis is not clear.

\section{Extrapolation of Immunogenicity Data}

Possible differences in the sensitivity of different populations to mount an anti-drug antibody (ADA) response have also been suggested as a reason to limit extrapolation of immunogenicity findings [4]. While it is true that the incidence of ADAs may differ in different indications-for example, due to patient factors, the use of co-medication, and dosing schedule - the relevance of this fact for biosimilarity assessment may be questioned [26]. Both clinical studies included in the dossier of CT-P13 reported comparable incidences and magnitude in ADA formation in studies including RA and AS patients, supporting the notion that the two molecules do not differ in their potential to elicit immune responses. In addition, higher order structure determination based on ELISA using multiple antibodies showed that comparable epitopes were recognized for CT-P13 and Remicade ${ }^{\circledR}$, suggesting the two products are similarly recognized by various antibodies [27]. Most importantly, antibodies against Remicade ${ }^{\circledR}$ have been found to cross react with CT-P13 in sera obtained from IBD patients, independent of glycosylation of the molecule [28]. Sera that were negative for Remicade ${ }^{\circledR}$ were also negative for CT-P13 [28]. Taken together, these data do not suggest any concerns on extrapolating immunogenicity across indications.

When determining immunogenicity, the regulatory objective is to compare the clinical impact of detected ADA by correlation with suitably sensitive clinical endpoints [29, 30]. It has been argued that in order to gain full insight into the longer-term outcomes, particularly the immunogenicity profile of biosimilars, comparative clinical data should be collected for more than 1 year-this last point is reportedly particularly pertinent in the CD setting for anti-TNF therapies [14]. However, most antibodies against TNF $\alpha$ inhibitors are detected during the first year of treatment, including in $\mathrm{CD}$, so there is really no scientific basis to support the need to collect data after 2 years [3133]. Even if antibodies were to develop after 1 year, there 
is no reason to expect that differences between a biosimilar and its reference product will only become manifest after this period. It is interesting that innovator products in most cases have not been required to provide data beyond 1 year in order to obtain marketing authorization. In the pivotal 52-week, double-blind maintenance study, M02-404, that was used to support approval of $\mathrm{Humira}^{\circledR}$ in CD, ADA levels were not monitored at all [34]. ADA formation was monitored for the maintenance of remission extension of the induction study, which included week 4 responders only, but there was an insufficient number of events to assess impact of ADA on efficacy [34]. So, requiring (comparative) immunogenicity data beyond 1 year lacks scientific rationale, and would raise the bar for biosimilars above that expected for innovator drugs, with obvious negative consequences for the affordability of these products.

\section{Global Naming Practices}

Once a biosimilar is approved, the medical community is informed primarily through the approved labeling/prescribing information of the product. The question then arises about whether it is helpful to include any comparative data from the biosimilarity exercise in the prescribing information. Generic products fully copy the label of their reference product, without including data on comparative pharmacokinetic studies to demonstrate bioequivalence. However, it has been suggested that the label of a biosimilar should clearly state which aspects have been studied and which aspects were granted based on extrapolation, while other commentators advocate identical labels $[35,36]$. Labeling requirements for biosimilars differ in various regions, as discussed in the following sections.

\subsection{EU}

The EMA has issued guidance on the labeling that places biosimilars in the same category as generics and hybrid products: "The information from the reference medicinal product's Summary of Product Characteristics (SmPC) that applies to the hybrid or biosimilar should be included in the SmPC of the hybrid or biosimilar" [37]. Current EU SmPCs do not differ between biosimilars and reference products in terms of wording-although the brand name has been replaced with the INN. The only relevant difference is that biosimilar SmPCs contain a black triangle, indicating that the product is subject to additional postauthorization monitoring by the EMA. Black triangles are included in the SmPC for 5 years or until the EMA's Pharmacovigilance Risk Assessment Committee decides to remove it from the list of medicines under additional monitoring. There is one authorized biosimilar that has a different SmPC from that of the reference product, namely Binocrit $^{\circledR}$. This reflects the historical regulatory context, in which subcutaneous administration of the reference product, Eprex ${ }^{\circledR}$, for treatment of renal anemia was temporarily contraindicated because of increased incidence of antibody-mediated pure red cell aplasia; this regulatory action precluded comparative clinical studies of Binocrit ${ }^{\circledR}$ with Eprex ${ }^{\circledR}$ in the preferred ('most sensitive') indication to assess comparable safety and efficacy. This led to the unique situation that, for epoetins, biosimilars initially did not receive the same indications as the reference product.

While the SmPC does not provide information on the comparative studies that were performed to demonstrate biosimilarity, in the EU detailed information on the extent of the data submitted by applicants can be found in European Public Assessment Reports (EPARs) [38]. The EPAR summarizes the weight of evidence forming the basis of the CHMP scientific opinion on the dossier. For a biosimilar product, the EPAR identifies the scale of any detected differences in physicochemical properties and discusses how in vitro pharmacological and clinical data confirm the biosimilar designation.

\subsection{US}

According to US legislation, biosimilars must utilize the same mechanism or mechanisms of action for the condition or conditions of use prescribed, recommended, or suggested in the proposed labeling and are prescribed for conditions that have been previously approved for the reference product [39]. Furthermore, the route of administration, the dosage form, and the strength of the biosimilar should be the same as those of the reference product. Nevertheless, also in the US, it is possible to obtain a license as a biosimilar for fewer than all indications for which the reference product is licensed [40]. The prescribing information of the first authorized biosimilar, filgrastim-sndz (Zarxio ${ }^{\circledR}$ ), is identical to its reference product Neupogen ${ }^{\circledR}$ with no reference to the studies performed during the biosimilarity exercise.

In addition to the prescribing information, FDA shares considerable data on the assessment of biosimilar products, although some items are redacted that contain proprietary or personal information. These documents, accessible via Drugs@FDA [41], may contain more detailed information than EPARs, encompassing chemistry, pharmacology, and clinical data.

\subsection{Other Regions}

Other regions have chosen different approaches. Health Canada has determined that biosimilars [in Canada named 
Subsequent Entry Biologics (SEBs)] will not be able to utilize the Product Monograph (PM) of the reference biologic drug in its entirety as that of its own products. This may be explained in part by the fact that subsequent entry biologics are authorized under the same legal pathway as new biologics, unlike the EU and US where biosimilars have a separate legal status [37]. The PM should state that the product is a SEB. It should include key data on which the decision for market authorization was made, including tables showing the results of the comparisons between the SEB and reference biologic drug and information on the indications approved for use (Table 1). There should be no claims for bioequivalence between the subsequent entry biologics and the reference biologic drug nor should clinical equivalence be claimed between the subsequent entry biologic and the reference biologic drug [37]. This has resulted in 'hybrid' labels that contain information both from the innovator and of the biosimilars. Health Canada also publishes a Summary of Basis of Decision for approved drugs that provides more detailed information on the Health Canada decision, but these are less detailed then the published FDA review documents and EPARs [42]. A similar approach has been taken in Australia where "relevant clinical trial information generated on the reference product and reported in the reference product PI may be incorporated into the PI for the biosimilar. However these data should be clearly identified as having been produced using the reference product not the biosimilar" [43]. For currently authorized biosimilars, this has resulted in product labels including a detailed description of the (clinical) comparability studies. Australia also shares more detailed information on the assessment procedures in Australian public assessment reports, which in content resemble EPARs [44]. Both in Canada and Australia, the prescribing information for generic medicinal products are identical to their reference products. For India we were not able to find regulatory assessment reports.

\section{Discussion}

Although the regulatory basis for extrapolation is comparable in all regulatory regions, regulatory agencies weigh data differently in reaching conclusions about the acceptability of extrapolation. The scientific rationale for differing regulatory decisions regarding the extrapolation of therapeutic indications for Remsima ${ }^{\circledR}$ is not cleararguably, more weight was given by the Canadian authority to uncertainty than to real evidence that different mechanisms of action actually influence the clinical efficacy of infliximab in the respective therapeutic indications. Regardless, the different decisions taken by regulatory agencies have led to calls to these agencies to clarify the scientific basis for extrapolation of indications $[4,5,14]$.

The decision of various regulatory agencies to allow a product on the market as a biosimilar, but with different authorized indications, has given rise to considerable confusion and raises some fundamental questions about what it means to be a biosimilar. Since the inception of the biosimilar regulatory framework, much effort has been directed to emphasize that biosimilars are not generics. While complexity of biologicals clearly justifies a tailored regulatory route, the outcome of the biosimilarity exercise should be a product that has demonstrated similarity to its reference product, allowing a biosimilar product to refer to the established efficacy and safety experience of the innovator product. In our opinion this should be a binary outcome; you either are, or you are not biosimilar to a given reference product. Granting some indications but not others is at odds with this concept. Of note, as has been highlighted in a recently published article, also generic medicinal products may not necessarily be identical to the reference product in all respects [45]. Thus, the difference in global regulatory practices applied to extrapolation of indications and prescribing information for biosimilars cannot be explained solely by 'non-identicality' of the physicochemical properties of the drug product, but are likely to be reflections of the different views of regulators throughout the world in weighing evidence to support biosimilarity.

EU guidance states that if relevant differences are observed between a biosimilar and a reference product, it is unlikely that biosimilarity will be established and a standalone development to support a 'full' marketing authorization should be considered instead $[17,37,46]$. Also, US guidance states that if an observed difference is considered clinically meaningful, this, in effect, precludes the product from being considered biosimilar to its reference product [47-49]. A recent opinion article written by Canadian regulators notes, that:

"The decision to extrapolate should be based primarily on the demonstration of similarity through extensive comparability studies that compare the physicochemical attributes and the biological activity between the biosimilar and reference product. Failure to demonstrate that the intended biosimilar and the reference product are highly similar at this stage precludes extrapolation to indications and uses for which the biosimilar mAb has not been studied. In fact, if similarity cannot be sufficiently demonstrated at this stage, sponsors should pursue a stand-alone authorization pathway." [17]

This raises some questions on the Canadian decision to authorize CT-P13 as an SEB, rather than deciding that 
Table 1 Biosimilar definitions and labeling practices in selected regulatory regions

\begin{tabular}{|c|c|c|}
\hline & Definition of biosimilar as defined in most current guidance & Label structure: biosimilars vs innovator \\
\hline EMA & $\begin{array}{l}\text { A biological medicinal product that contains a version of the } \\
\text { active substance of an already authorised original biological } \\
\text { medicinal product (reference medicinal product) in the EEA. } \\
\text { Similarity to the reference medicinal product in terms of quality } \\
\text { characteristics, biological activity, safety and efficacy based on a } \\
\text { comprehensive comparability exercise needs to [have been] } \\
\text { established [41] }\end{array}$ & $\begin{array}{l}\text { Identical (the SmPCs of biosimilar products contain the addition } \\
\text { that the product is a biosimilar) }\end{array}$ \\
\hline $\begin{array}{l}\text { Health } \\
\text { Canada }\end{array}$ & $\begin{array}{l}\text { [A subsequent entry biologic is] A biologic drug that enters the } \\
\text { market subsequent to a version previously authorized in Canada, } \\
\text { and with demonstrated similarity to a reference biologic drug. } \\
\text { An SEB relies in part on prior information regarding safety and } \\
\text { efficacy that is deemed relevant due to the demonstration of } \\
\text { similarity to the reference biologic drug [35] }\end{array}$ & $\begin{array}{l}\text { Non-identical monographs, some information based on data } \\
\text { from reference product, other data from comparability studies } \\
\text { also included }\end{array}$ \\
\hline FDA & $\begin{array}{l}\text { A biological product that is approved based on showing that it is } \\
\text { highly similar to an FDA-approved biological product, known as } \\
\text { a reference product, and has no clinically meaningful differences } \\
\text { in terms of safety and effectiveness from the reference product. } \\
\text { Only minor differences in clinically inactive components are } \\
\text { allowable in biosimilar products [42] }\end{array}$ & Identical \\
\hline India & $\begin{array}{l}\text { A biological product/drug produced by genetic engineering } \\
\text { techniques and claimed to be 'similar' in terms of safety, } \\
\text { efficacy and quality to a reference biologic, which has been } \\
\text { granted a marketing authorization in India by DCGI on the basis } \\
\text { of a complete dossier, and with a history of safe use in India [24] }\end{array}$ & $\begin{array}{l}\text { Hybrid label } \\
\text { Reference to biosimilarity studies (based on Exemptia label) }\end{array}$ \\
\hline Australia & $\begin{array}{l}\text { A version of an already registered biological medicine that: } \\
\text { has a demonstrable similarity in physicochemical, biological } \\
\text { and immunological characteristics, efficacy, and safety, based on } \\
\text { comprehensive comparability studies } \\
\text { has been evaluated by the TGA according to this guideline and } \\
\text { other relevant EU guidelines adopted by the TGA [43] }\end{array}$ & $\begin{array}{l}\text { Non-identical monographs, some information based on data } \\
\text { from reference product, other data from comparability studies } \\
\text { also included }\end{array}$ \\
\hline
\end{tabular}

DCGI Drug Controller General of India, EEA European Economic Area, SEB subsequent entry biologic, SmPC Summary of Product Characteristics, $T G A$ Therapeutic Goods Administration

stand-alone development would be required to obtain marketing authorization. The observed differences in regulatory decision making surrounding CT-P13 seems to represent a difference in the approach to data interpretation, rather than a difference in the legislative basis of the approval process. The content of the labels of biosimilars throughout the world also reflect the dilemmas that regulators are faced with: on the one hand, to authorize products that have demonstrated similarity to an existing product but, on the other hand, also to inform physicians of the data that was presented and upon which this decision is based. Regulators need to strike a balance between providing the information without creating a situation that is confusing to prescribers. Providing different labels for biosimilars that have demonstrated comparability to an existing reference product could strengthen a perception that biosimilars are different from their reference product. In addition, the basis of establishing biosimilarity is a substantial database of comparative product quality data, which may not be informative for HCPs and is also not included in, for example, the Canadian label. The biosimilarity exercise also includes a directly comparative evaluation of immunogenicity, often using bioanalytical methods of higher sensitivity than those used to support the authorization of the reference product - these data are also not likely to be included in the prescribing information. Physicians looking only at the label could conclude that the evidence base is meager compared with the innovator drug, thereby not acknowledging the different regulatory approach of biosimilars. While there are many other sources of information than the label (e.g., EPARs in the EU and review documents published by the FDA), this information may not be easily digestible for prescribers.

While recommended in most cases, randomized clinical studies have limitations in detecting differences between products that have been demonstrated to be structurally similar by extensive analytical and in vitro pharmacological characterization. Given their complexity and concerns for immunogenicity, clinical trials are an important tool in confirming comparable clinical efficacy and establishing 
comparable immunogenicity profiles. However, clinical efficacy data are not a prerequisite for being authorized as a biosimilar. As experience with biosimilars is increasing, so is the confidence in the ability to establish comparability using analytical and in vitro methods. Currently, EU regulators are contemplating prerequisites for waiving confirmatory clinical efficacy studies for well characterisable products like G-CSF (granulocyte-colony stimulating factor), which will bring the biosimilarity exercise closer to the generic pathway [50].

\section{Conclusions}

The principles of establishing biosimilarity are to demonstrate structural and functional similarity to a reference product using the most discriminatory analytical methods. These data are supported where necessary by focused clinical evaluation using conditions that are adequately sensitive to evaluate real risks that cannot be addressed solely by analytical data. Allowing products on the market that do not have the same authorized indications will create considerable confusion about the concept of biosimilarity. The success of biosimilars will depend on how they will be able to be interchanged with the reference product and other biosimilars in clinical practice. If multiple biosimilars are allowed on the market with different approved uses, this will create a complex situation that will add hurdles for the successful uptake of biosimilars.

Despite the increasing number of countries that have adopted biosimilar guidelines, there are clear differences in local requirements in terms of weight of evidence and data interpretation, labeling and naming of biosimilars. Such divergent regulatory decisions on a key aspect of the biosimilarity exercise like extrapolation do not help to solve the confusion that exists at the level of healthcare professionals and patients about biosimilars. Clearly there is a need for global harmonization of the concept of biosimilarity and regulatory requirements for biosimilars in the various regulatory regions.

\section{Compliance with Ethical Standards}

Conflict of Interest HCE has no conflicts of interest relevant for the content of this manuscript, he has participated in meetings sponsored by Dr. Reddy's and AbbVie unrelated to the submitted work. PC has received consulting fees from different companies in respect of strategic and operational advice relating to biopharmaceutical development; he is self-employed, and serves as a Member of the NDA Advisory Board, a company that provides market access consultancy services to pharmaceutical companies.

Funding No sources of funding were used to assist in the preparation of this study.

Author Contributions Both authors provided intellectual contributions to the content of the manuscript and approved the final version. HCE was the primary author.
Open Access This article is distributed under the terms of the Creative Commons Attribution-NonCommercial 4.0 International License (http://creativecommons.org/licenses/by-nc/4.0/), which permits any noncommercial use, distribution, and reproduction in any medium, provided you give appropriate credit to the original author(s) and the source, provide a link to the Creative Commons license, and indicate if changes were made.

\section{References}

1. Weise M, Kurki P, Wolff-Holz E, Bielsky MC, Schneider CK. Biosimilars: the science of extrapolation. Blood. 2014;124:3191-6.

2. Schneider CK, et al. Setting the stage for biosimilar monoclonal antibodies. Nat Biotechnol. 2012;30:1179-85.

3. Ebbers HC, et al. Measures of biosimilarity in monoclonal antibodies in oncology: the case of bevacizumab. Drug Discov Today. 2013;18:872-9.

4. Feagan BG, et al. The challenge of indication extrapolation for infliximab biosimilars. Biologicals. 2014;42:177-83.

5. Lee $\mathrm{H}$. Is extrapolation of the safety and efficacy data in one indication to another appropriate for biosimilars? AAPS J. 2014;16(1):22-6. doi:10.1208/s12248-013-9534-y.

6. Schellekens H, Moors E. Biosimilars or semi-similars? Nat Biotechnol. 2015;33:19-20.

7. Schneider CK. Biosimilars in rheumatology: the wind of change. Ann Rheum Dis. 2013;72:315-8.

8. Argüelles-Arias F, Barreiro-de-Acosta M, Carballo F, Hinojosa J, Tejerina T. Joint position statement by "Sociedad Española de Patología Digestiva" (Spanish Society of Gastroenterology) and "Sociedad Española de Farmacología" (Spanish Society of Pharmacology) on biosimilar therapy for inflammatory bowel disease. Revista Española de Enfermedades Digestivas. 2013;105:37-43.

9. American College of Rheumatology. Position statement. Biosimilars. 2011. http://www.rheumatology.org/Practice/ Clinical/Position/Position_Statements. Accessed 24 Sept 2013.

10. Espinosa Morales, $\mathrm{R}$ et al. Biosimilar drugs in Mexico: position of the Mexican College of Rheumatology, 2012. Rheumatology. 2013;09:113-116.

11. World Health Organisation. Guidelines on evaluation of similar biotherapeutic products (SBPs). 2009. http://www.who.int/ biologicals/areas/biological_therapeutics/BIOTHERAPEUTICS_ FOR_WEB_22APRIL2010.pdf. Accessed 11 Feb 2013.

12. Jelkmann W. Physiology and pharmacology of erythropoietin. Transfus Med Hemother. 2013;40:302-9.

13. Health Canada. Summary basis of decision (SBD) for inflectra. 2014. http://www.hc-sc.gc.ca/dhp-mps/prodpharma/sbd-smd/ drug-med/sbd_smd_2014_inflectra_159493-eng.php\#sbd. Accessed 10 Feb 2015.

14. Schellekens H, Lietzan E, Faccin F, Venema J. Biosimilar monoclonal antibodies: the scientific basis for extrapolation. Expert Opin Biol Ther 2015;1-14.

15. Mitoma $\mathrm{H}$, et al. Mechanisms for cytotoxic effects of anti-tumor necrosis factor agents on transmembrane tumor necrosis factor alpha-expressing cells: comparison among infliximab, etanercept, and adalimumab. Arthritis Rheum. 2008;58:1248-57.

16. European Medicines Agency. Inflectra. European Public Assessment Report. 2013. http://www.ema.europa.eu/ema/index. jsp?curl=pages/medicines/human/medicines/002778/human_med_ 001677.jsp\&mid=WC0b01ac058001d124. Accessed 6 Dec 2013.

17. Scott BJ, Klein AV, Wang J. Biosimilar monoclonal antibodies: A canadian regulatory perspective on the assessment of clinically relevant differences and indication extrapolation. Pharmacol: JClin; 2014.

18. Louis $\mathrm{E}$, et al. Association between polymorphism in $\mathrm{IgG} \mathrm{Fc}$ receptor IIIa coding gene and biological response to infliximab in Crohn's disease. Aliment Pharmacol Ther. 2004;19:511-9. 
19. Moroi R, et al. FCGR3A-158 polymorphism influences the biological response to infliximab in Crohn's disease through affecting the ADCC activity. Immunogenetics. 2013;65:265-71.

20. Horiuchi T, Mitoma H, Harashima S, Tsukamoto H, Shimoda T. Transmembrane TNF-alpha: structure, function and interaction with anti-TNF agents. Rheumatology (Oxford). 2010;49: 1215-28.

21. Tracey D, Klareskog L, Sasso EH, Salfeld JG, Tak PP. Tumor necrosis factor antagonist mechanisms of action: a comprehensive review. Pharmacol Ther. 2008;117:244-79.

22. Exemptia Prescribing Information. http://www.Exemptia.com. Accessed 8 May 2015.

23. Bandyopadhyay S, et al. Physicochemical and functional characterization of a biosimilar adalimumab ZRC-3197. Biosimilars. 2015;5:1-18.

24. Government of India. Guidelines on similar biologics: regulatory requirements for Marketing Authorization in India. 2012. http:// www.cdsco.nic.in/Bio.Similar.Guideline.pdf. Accessed 30 Jan 2013.

25. Jani RH, Gupta R, Bhatia G, Rathi G, Ashok Kumar P, Sharma R, Kumar U, Gauri LA, Jadhav P, Bartakke G, Haridas V, Jain D, Mendiratta SK. A prospective, randomized, double-blind, multicentre, parallel-group, active controlled study to compare efficacy and safety of biosimilar adalimumab (Exemptia; ZRC-3197) and adalimumab (Humira) in patients with rheumatoid arthritis. Int $\mathbf{J}$ Rheumat Dis. 2015. doi:10.1111/1756-185X.12711.

26. Moss AC, Brinks V, Carpenter JF. Review article: immunogenicity of anti-TNF biologics in IBD-the role of patient, product and prescriber factors. Aliment Pharmacol Ther. 2013;38:1188-97.

27. Jung SK, et al. Physicochemical characterization of Remsima. MAbs. 2014;6:1163-77.

28. Ben-Horin S, Yavzori M, Benhar I, Fudim E, Picard O, Ungar B, Lee S, Kim S, Eliakim R, Chowers Y. Cross-immunogenicity: antibodies to infliximab in Remicade-treated patients with IBD similarly recognise the biosimilar Remsima. Gut. 2015. doi:10. 1136/gutjnl-2015-309290.

29. Food and Drug Administration. Guidance for industry immunogenicity assessment for therapeutic protein products. 2014. http:// www.fda.gov/downloads/drugs/guidancecomplianceregulatory information/guidances/ucm338856.pdf. Accessed 15 August 2015.

30. European Medicines Agency. Guideline on immunogenicity assessment of monoclonal antibodies intended for in vivo clinical use (EMA/CHMP/BMWP/86289/2010). 2012. http://www.ema. europa.eu/docs/en_GB/document_library/Scientific_guideline/ 2012/06/WC500128688.pdf. Accessed 15 Sept 2015.

31. Ungar B, Chowers Y, Yavzori M, Picard O, Fudim E, Har-Noy O, Kopylov U, Eliakim R, Ben-Horin S, ABIRISK consortium. The temporal evolution of antidrug antibodies in patients with inflammatory bowel disease treated with infliximab. Gut. 2014;63(8):1258-64. doi:10.1136/gutjnl-2013-305259.

32. Bartelds GM, et al. Development of antidrug antibodies against adalimumab and association with disease activity and treatment failure during long-term follow-up. JAMA. 2011;305:1460-8.

33. Baert F, Kondragunta V, Lockton S, Vande Casteele N, Hauenstein S, Singh S, Karmiris K, Ferrante M, Gils A, Vermeire S. Antibodies to adalimumab are associated with future inflammation in Crohn's patients receiving maintenance adalimumab therapy: a post hoc analysis of the Karmiris trial. Gut. 2015. doi:10.1136/gutjnl-2014-307882.

34. European Medicines Agency. Humira European public assessment report EMEA/H/C/481-482/II/33. 2007. http://www.ema. europa.eu/docs/en_GB/document_library/EPAR_-_Scientific_ Discussion_-_Variation/human/000481/WC500050875.pdf. Accessed 25 Aug 2015.
35. European Medicines Agency. Overview of comments received on 'Guideline on similar biological medicinal products containing monoclonal antibodies' (EMA/CHMP/BMWP/403543/2010). 2012. http://www.ema.europa.eu/docs/en_GB/document_library/ Other/2012/06/WC500128687.pdf. Accessed 24 Sept 2013.

36. European Biopharmaceutical Enterprises. Tell me the whole story: the role of product labelling in building user confidence in biosimilars in Europe. Gen Biosimil Initiative J (GaBI J). 2014;3:188-92.

37. Health Canada. Guidance for sponsors: information and submission requirements for subsequent entry biologics (SEBs). 2010. http:// www.hc-sc.gc.ca/dhp-mps/alt_formats/pdf/brgtherap/applic-demande/ guides/seb-pbu/seb-pbu-2010-eng.pdf. Accessed 30 Jan 2013.

38. European Medicines Agency. European public assessment reports. 2015. http://www.ema.europa.eu/ema/index.jsp?curl=pages/ medicines/landing/epar_search.jsp\&mid=WC0b01ac058001d124.

39. U.S. Senate. Biologics Price Competition and Innovation Act of 2009. 2009;703:351.

40. Food and Drug Administration. Guidance for Industry on Biosimilars: Q \& As Regarding Implementation of the BPCI Act of 2009: Questions and Answers Part I. 2012. http://www.fda. gov/Drugs/GuidanceComplianceRegulatoryInformation/Guidances/ ucm259809.htm\#Q6. Accessed 22 Sept 2015.

41. Food and Drug Administration. Drugs@FDA. http://www. accessdata.fda.gov/scripts/cder/drugsatfda/index.cfm. Accessed 22 Sept 2015.

42. Health Canada. Summary basis of decision (SBD) documents. Drugs. 2012. http://www.hc-sc.gc.ca/dhp-mps/prodpharma/sbdsmd/drug-med/index-eng.php. Accessed 06 Nov 2015.

43. Therapeutic goods Administration. Evaluation of biosimilars. 2015. https://www.tga.gov.au/book/labels-product-informationpi-and-consumer-medicine-information-cmi-biosimilars. Accessed 21 Sept 2015.

44. Therapeutic goods Administration. Australian Public Assessment Reports for prescription medicines (AusPARs). https://www.tga. gov.au/australian-public-assessment-reports-prescription-medicinesauspars. Accessed 06 Nov 2015.

45. van der Plas RM, van Zwieten-Boot BJ, Hoefnagel M, Jongen PMJM. The EU regulatory approach to generics and biosimilars is essentially similar. Generics Biosimil Initiative J (GaBI J). 2015;4:9-10.

46. European Medicines Agency. Guideline on similar biological medicinal products containing biotechnology-derived proteins as active substance: non-clinical and clinical issues (EMEA/CHMP/ BMWP/42832/2005 Rev1). 2015. http://www.ema.europa.eu/ docs/en_GB/document_library/Scientific_guideline/2015/01/WC 500180219.pdf. Accessed 18 May 2015.

47. Food and Drug Administration. Clinical pharmacology data to support a demonstration of biosimilarity to a reference product DRAFT GUIDANCE. 2014. http://www.fda.gov/downloads/ Drugs/GuidanceComplianceRegulatoryInformation/Guidances/ UCM397017.pdf. Accessed 12 Oct 2015.

48. Food and Drug Administration. Quality considerations in demonstrating biosimilarity of a therapeutic protein product to a reference product. 2015. http://www.fda.gov/downloads/Drugs/ GuidanceComplianceRegulatoryInformation/Guidances/ UCM291134.pdf. Accessed 4 Nov 2015.

49. Food and Drug Administration. Scientific considerations in demonstrating biosimilarity to a reference product. 2015. http:// www.fda.gov/downloads/Drugs/GuidanceComplianceRegulatory Information/Guidances/UCM291128.pdf. Accessed 18 May 2015.

50. European Medicines Agency. Concept paper on the revision of the guideline on non-clinical and clinical development of similar biological medicinal products containing recombinant granulocyte-colony stimulating factor (EMA/CHMP/BMWP/214262/ 2015). 2015. http://www.ema.europa.eu/docs/en_GB/document_ library/Scientific_guideline/2015/07/WC500190635.pdf. Accessed 26 Aug 2015. 